\title{
Biological Association and Expressions of NOS3 \& SOD2 in Non-Diabetic Senile Cataractogenesis
}

\author{
Shamim Mushtaq1 ${ }^{*}$, Meraj Zehra1, Ayesha Khan², Mehwish Ahmed², Rubina Ghani', Nikhat Ahmed ${ }^{4}$ \\ ${ }^{1}$ Department of Biochemistry, Ziauddin University, Karachi, Pakistan \\ ${ }^{2}$ Department of Biochemistry, University of Karachi, Karachi, Pakistan \\ ${ }^{3}$ Jinnah Medical and Dental College, Karachi, Pakistan \\ ${ }^{4}$ Research Department, Ziauddin University, Karachi, Pakistan \\ Email: ${ }^{\star}$ shamim.mushtaq@zu.edu.pk, *shamim.mushtaq@gmail.com
}

How to cite this paper: Mushtaq, S., Zehra, M., Khan, A., Ahmed, M., Ghani, R. and Ahmed, N. (2016) Biological Association and Expressions of NOS3 \& SOD2 in Non-Diabetic Senile Cataractogenesis. Advances in Enzyme Research, 4, 87-97.

http://dx.doi.org/10.4236/aer.2016.43009

Received: July 22, 2016

Accepted: September 6, 2016

Published: September 9, 2016

Copyright $\odot 2016$ by authors and Scientific Research Publishing Inc. This work is licensed under the Creative Commons Attribution International License (CC BY 4.0).

http://creativecommons.org/licenses/by/4.0/

\begin{abstract}
Aim: To evaluate the functional relationship between the nitric oxide synthase (NOS) and superoxide dismutase (SOD) enzymes in the pathogenesis of human senile cataract lenses of non-diabetic patients. Methods: Total solubilized proteins from human cataract lens were compared with normal lens (control) by 2-Dimenstional gel electrophoresis (2-DE). Proteins with different abundances were identified by matrix-assisted laser desorption/ionization time-of-flight mass spectrometry (MALDI-TOF-MS). Western blot analysis was used to verify the changes in expression of NOS3 and SOD2. A further functional association of NOS3 with SOD2 and other proteins was seen by STRING 8.3 databases. Results: In the 2-DE maps, the cataract and normal lens proteins migrated in the region of $\mathrm{pH} 3-10$ with a relative molecular weight of $20-130 \mathrm{kDa}$. Approximately two protein spots with differential intensity were detected as NOS3 and SOD2 using MALDI-TOF-MS. Western blot analysis showed high expression of NOS3 in cataract and SOD2 in normal lens samples. String interaction network revealed strong interactions between NOS3 and SOD2 at high confidence score, which is helpful in characterization of functional abnormalities that may be a causative factor in the pathogenesis of cataract. Conclusion: This study will offer new avenues for mechanistic evaluation and future prevention of cataractogensis. However, large scale studies will be required to evaluate the effect of this interaction on the clinical outcome in human cataract.
\end{abstract}

\section{Keywords}

Cataract, Free Radical, Nitric Oxide Synthase, Superoxide Dismutase, Reactive Oxygen Species, Non-Diabetic Cataract 


\section{Introduction}

Cataract is the major cause of visual disability and it is estimated that over 17 million people are blind worldwide [1]. Cellular damage or oxidative damage caused by reactive intermediates (ROI) acts as a major cause in the progression of numerous age-related disorders, such as age related macular degeneration, and age-related cataract [2]. Among many contributing factors, age is by far the most apparent risk factor for cataract development [3] [4].

Previous studies have investigated differences in age related lens proteomic profiles with diabetic cataract to determine the mechanism underlying the formation of diabetic and non-diabetic cataract [5] [6]. While comprehensive analysis of non-diabetic age related cataract has not been done to date but has the potential to explore important information regarding the pathogenesis of non-diabetic age related cataract. According to the free radical theory of ageing, [7] oxidative damage caused by free-oxygen radicals and other reactive oxygen species (ROS) contributes to the development of age-related cataract [8]-[15]. In the lens, both the ROS like superoxide, nitric oxide (NO) [16] and the glycation of proteins may initiate toxic biochemical reactions, leading to extensive damage [17].

Nitric oxide (NO) generated by nitric oxide synthases (NOS3), and known as a detrimental free radical, play an important role in the various physiological, pathological and aging process [18] [19]. Various biological functions are controlled by NO production which can be served as a second messenger intracellularly and extracellularly as conveyor of information between cells. However, excessive NO production can result in cellular damage via various mechanisms, which include the formation of highly reactive free radicals such as peroxynitrite and its activity is strongly influenced by its concentration [20]. In addition, NO levels in the aqueous humor increase with age and in patients with age-related cataract [21] [22]. However, the precise mechanism is not fully understood.

Antioxidants such as ascorbic acid and antioxidant enzymes like superoxide dismutase (SOD), catalase are responsible for neutralizing the harmful effects of the ROS [23] [24]. Antioxidant enzymes work with reducing systems and protein repair systems to protect against ROS-induced damage. In the mitochondria matrix, MnSOD (SOD2) converts the superoxide anion, which is generated by the electron transport chain, into hydrogen peroxide. By regulating the level of SOD2, lens epithelial cells can overcome oxidative stress and elevated level of SOD1 protects the lens from $\mathrm{H} 2 \mathrm{O} 2$-mediated damage [25]. ROS due to its instability and rapid reactions is difficult to detect; therefore study on antioxidant enzyme in cataract lens is most reliable alternate.

The present study investigated the level of expressions and interaction of enzymes NOS3 and SOD2 with respect to non-diabetic senile group of patient's cataract lens. We also tried to explore the role of these enzymes in the development of non-diabetic cataract and hoped to find an association between NOS3 molecule and SOD2 in the development of human cataract. In the future, association of these enzymes may be used as an alternative way to prevent cataract progression and will be important for a better 
understanding of catractogensis.

\section{Materials and Methods}

\subsection{Tissue Collection}

The investigation was approved by the Institutional Ethical Committee and informed consent was obtained from the study patients. In this study, total $n=30$ non-diabetic senile patients with nuclear cataract, 20 males and 10 females (age range, 45 to 75 years); and age-matched normal lenses ( $n=10), 6$ males and 4 females (age range, 40 to 70 years old) were obtained from LRBT (Layton Rahmatulla Benevolent Trust, Karachi) during surgery and after normal lenses analysis. All normal lenses did not reveal any opacity, thereby confirming their control samples status.

1) Inclusion criteria

All patients were above the age of 40 years, had no history of diabetes and smoking. They had normal serum glucose values (range $65-110 \mathrm{mg} / \mathrm{dl}$ ) and HbA1c. They were not taking any supplements such as vitamins or antioxidants.

2) Exclusion criteria

History of any ocular eye surgery, diabetes, ocular trauma, corneal scar, dry eye syndrome, glaucoma, uveitis and chronic systemic illness. Patients with steroid medications were also excluded.

\subsection{Protein Extraction}

The lens tissue was homogenized with homogenizer in $1 \mathrm{ml}$ of $20 \mathrm{mM}$ phosphate buffer containing proteases inhibitor ( $\mathrm{pH}$ 7.0). This suspension was centrifuged at $20,000 \mathrm{X} \cdot \mathrm{g}$ for 30 minutes at $4^{\circ} \mathrm{C}$ to remove insoluble material. The supernatant was separated in an eppendorf and stored at $-80^{\circ} \mathrm{C}$ before use. Protein concentrations of all the samples were determined by bicinchoninic acid (BCA, Thermo Fisher Scientific) method [26].

\subsection{Two-Dimensional Gel Electrophoresis (2-DE)}

Isoelectric focusing (IEF) was carried out as described previously [27] with immobiline dry strips kit (GE Healthcare Life Science, NJ, USA) using multiphor II electrophoresis system according to the manufacturer's instructions. Briefly IPG (Immobiline PH gradient) strips $(11 \mathrm{~cm}, \mathrm{pH} 3-10)$ were allowed to rehydrate overnight in the rehydration buffer containing $8 \mathrm{M}$ urea, 2\% CHAPS, $0.1 \mathrm{M}$ DTT, and 0.5\% IPG buffer, the strips were overlaid with mineral oil. Equal amounts of epithelial proteins from both migrating (48 hours) and non-migrating cornea were solubilized in sample solution containing $9 \mathrm{M}$ urea, $50 \mathrm{mM} \mathrm{DTT}, 2 \%$ pharmalyte $(3$ - 10) and 0.5\% triton X-100 and loaded onto caps at the cathodic end of the rehydrated IPG strips, and covered with low-viscosity paraffin oil. IEF was run at $150 \mathrm{~V}$ for an hour. The voltage was progressively increased from 300 to $600 \mathrm{~V}$ during first three hours, followed by $3500 \mathrm{~V}$ for two hours. The IPG strips were equilibrated for 15 minutes with a solution of $0.05 \mathrm{M}$ Tris- $\mathrm{HCl}, 6$ $\mathrm{M}$ urea, $30 \%$ glycerol and $1 \%$ SDS. Proteins were separated on $10 \%$ gels by standard so- 
dium dodecyl sulfate polyacrylamide gel (SDS-PAGE).

\subsection{Mass Spectrometry}

Single protein spots were excised from the 2-D gels and in-gel digested as described previously [27] [28]. The tryptic fragments were analyzed by MALDI MS (Voyager DE-PRO; Applied Biosystems) and, where necessary, also by ESI-Q-TOF MS/MS (Micromass) for sequence information. Samples for MALDI analysis were mixed in a 1:1 $\mathrm{v} / \mathrm{v}$ ratio with a saturated CHCA solution in $50 \%$ ACN/0.1\% TFA. Samples for the ESI analysis were introduced via gold-coated nano-ES needles (Protana). A capillary voltage of $800-1000 \mathrm{~V}$ was applied together with a cone voltage of $40-45 \mathrm{~V}$ and collision energy of $4.2 \mathrm{eV}$. The sample aerosol was desolvated in a stream of nitrogen. During the CID, the collision energy was in the range of $15-30 \mathrm{eV}$ with argon as the collision gas. Proteins were identified from peptide masses and amino acid sequences using NCBI blast search (http:// www.ncbi.nlm.nih.gov/blast/blast.cgi).

\subsection{Western Blot Analysis}

The protein extract was dissolved in sample diluting buffer and resolved on 10\% SDSPAGE gel. Protein bands were transferred to PVDF membrane and then blocked using $5 \%$ bovine serum albumin (BSA) solution for an hour. The membrane was incubated individually with respective primary antibodies for NOS3 \& SOD2 (1:500) overnight. After washing, the blot was incubated with secondary antibodies horse radish peroxidase (HRP) conjugated goat anti-rabbit. The bands were visualized using TMB Western blotting detection reagents (Thermo Fisher Scientific).

\subsection{Statistical Analysis}

NOS3 and SOD2 densitometric analysis expressions data are presented as the mean \pm SD. Statistical analyses were carried out by Graph Pad Prism 5 software (San Diego California USA, www.graphpad.com) $\mathrm{p}<0.05$ was taken as significant. The level of significance was determined at $95 \%$ confidence level.

\subsection{The Predicted Functional Association Network of NOS3 and SOD2}

The functional association network of the identified proteins was generated through protein interaction network STRING $8.3 \mathrm{http}$ ://string-db.org. Identified proteins were submitted to database to generate and to specifically figure out functional association network of the NOS3 and SOD2.

\section{Results}

\subsection{Two-Dimensional Analysis of Proteins of Cataract and Non-Cataract Samples}

To examine the differences in protein expressions between cataract and non-cataract, whole-tissue extracts were prepared and analyzed by 2-DE electrophoresis. Representative 2-DE gels show (Figure 1(a) \& Figure 1(b)) with loading of an equal amount of 


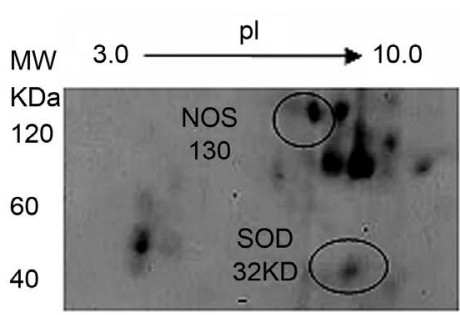

(a)

$\beta$-Actin

(c)

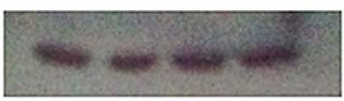

(d)



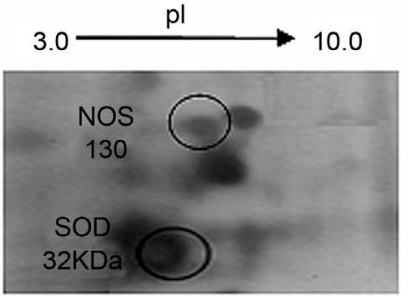

(b)

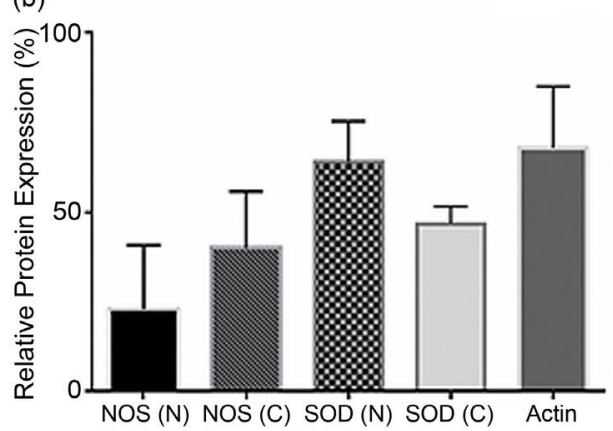

Figure 1. Two-dimensional gel electrophoresis (2-DE) gel image of the non-diabetic senile (a) Normal lens proteins and (b) cataract lens. The proteins were separated by 2-DE and stained with Coomassie brilliant blue. This spot was excised and analyzed by MALDI-TOF mass spectrometry, (c) $\beta$-Actin used as loading control, (d) Western blot analysis of NOS3 and SOD2 was done in cataract (c) and normal (N) lens samples (e) graph indicates relative NOS3 \& SOD2 expression compared with normal $(\mathrm{N})$ lens. Values $(\mathrm{n}=8)$ are expressed as mean $\pm \mathrm{SD}$. Comparison between different groups, indicate significant difference at $\mathrm{p}<0.05$. Groupings are N: Normal, C: Cataract, NOS: Nitricoxide Synthase, SOD: Superoxide dismutase.

total protein $(100 \mu \mathrm{g} / \mathrm{gel})$ revealed approximately 22 protein spots in normal and 17 spots in cataract sample. Lens protein spots in both sample types were distributed in the following region: isoelectric point $(\mathrm{PI})(\mathrm{pH}=3-10)$ and relative molecular weight (RMW) 130 - $20 \mathrm{kDa}$. All gel spots showing significant changes in abundance were highlighted and few protein spots with at least 3-fold difference in abundance between cataract and normal lens samples were detected. Moreover, two protein spots $130 \mathrm{kDa}$ and $32 \mathrm{kDa}$ demonstrated higher abundance in the cataract group than in the normal samples.

\subsection{Western Blot Analysis}

It demonstrated a potential distinction in the expression of NOS3 and SOD2 ( $n=3$ each) with respect to the cataract and non-cataract samples (Figure 1(c) \& Figure 1(d)). Furthermore, an increase in the expression of SOD (5\%) and NOS3 (12\%) (p > 0.05) in normal samples. Densitometric analysis NOS3 and SOD2 as compared to control accurately reflects the contribution that each protein makes in the progression of cataractractogensis (Figure 1(e)).

\subsection{Spot Analysis and Mass Spectrometry Identification of Cataract and Normal Lens Proteins}

To identify the proteins whose spots indicated changed expression, the differentially 
expressed spots were excised from the gels and subjected to in-gel digestion with trypsin, and the resulting peptides were identified by MALDI-TOF-MS as described in Material and Methods. From a total of three differentially expressed protein spots identified by MS, two were identified as nitric oxide synthase (NOS3) and Superoxide dismutase (SOD2) with the matched sequence coverage of $46 \%$; the and $60 \%$ (Table 1). However, the remaining spots were not identified because of interference by the dopant (maybe). Moreover, the expression of the two identified proteins was consistently increased in cataract sample relative to normal.

\subsection{The Functional Association Network of Identified Proteins}

The functional association network of the candidate proteins was generated through protein interaction network, STRING 8.3. The interaction patterns are helpful in providing a better understanding of the protein functional activities. A strong interaction of SOD2 and NOS3 with several other important proteins is evident with a high confidence score $(>0.7)$ Figure 2.

Table 1. Differentially expressed NOS3 and SOD2 proteins in human cataract lens as identified by MS/MS.

\begin{tabular}{ccccccc}
\hline Acc \# & Name & Abbr & $\begin{array}{c}\text { Thr. pI } \\
\text { Mass kDa }\end{array}$ & Score & Peptide Match & \% age Cov \\
\hline CAA53950 & $\begin{array}{c}\text { Nitric Oxide } \\
\text { Synthase, } \\
\text { endothelial/eNOS } \\
\text { AAA62278 }\end{array}$ & NOS3 & $5.8 / 130$ & 140 & $\begin{array}{c}\text { lcmdeydvvs pqllrllstl cafaravdtr } \\
\text { aeglqllpgl pqllrllstl svssapsthp } \\
\text { geihltvavl }\end{array}$ & 74 \\
& Dismutase & SOD2 & $4.5 / 32$ & 70 & gcestgphynpl & 40 \\
\hline
\end{tabular}

Accession no. is obtained from SWISS/Prot and \% age Coverage refers to the percentage of protein sequence coverage, determined by number of matched peptides. Acc: accession number; Abb; abbreviation; Thr. pI: theoretical isoelectric point; \% age. Cov: percent coverage.

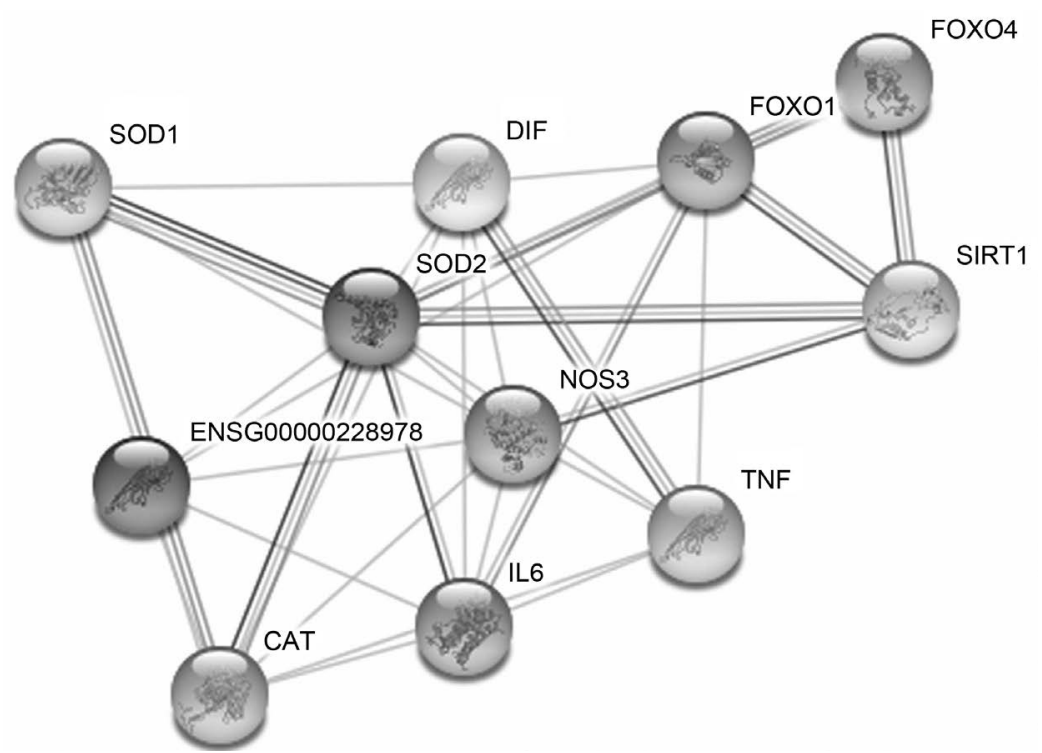

Figure 2. In Silico analysis of NOS3 and SOD2: A functional association network analysis. 
High-confidence protein-protein interaction network of identified proteins derived from the STRING database (http://string-db.org/). Each protein is represented as a node with edged interactions. NOS3 nitric oxide synthase 3 (endothelial cell), produce nitric oxide (NO): superoxide dismutase 2, mitochondrial; Destroys radicals which are normally produced within the cells: catalase; occurs in respiring organism and serves to protect cells from hydrogen peroxide: Tumor necrosis factor Precursor (TNF-alpha): sirtuin (silent mating type information regulation 2 homolog): interleukin 6 (interferon, beta 2); Cytokine with a wide variety of biological functions: tumor necrosis factor (TNF super family, member 2): ENSG00000228978; Tumor necrosis factor (TNF super family, member 2) fragment: FOXO1; fork head box O1; Transcription factor: FOXO\$; fork head box O4; Transcription factor involved in the regulation of the insulin signaling pathway.

\section{Discussion}

Reactive oxygen species (ROS) in the lens, causing biochemical changes that gradually disarrange the lens proteins, light scattering and loss of transparency which induced cataract development. Cataract is considered a major cause of visual impairment and it is found to be elevated in diabetic patients [29] [30]. Continuous chronic exposure with ROS may lead to age-related cataract however, in diabetes mellitus due to increased glucose levels causes increased generation of ROS that could lead to cataract formation. Furthermore, patients with diabetes mellitus have higher complication rates from cataract surgery [31]. However, previous study showed combination of superoxide and NO contributes to diabetic cataractogenesis in SOD null mice [32].

The present study demonstrates the interaction between NOS3 (eNOS) and SOD2 and how this interaction correlates with the etiology of non-diabetic senile cataract. This study also explore that SOD is important for the protection against age-related and non-diabetes cataract development. In contrast, Eva and his group reported that combination of high glucose and absence of SOD1 increases the formation of cataract and that nitric oxide probably contributes to this process [33].

In our study SOD expression was high than normal lens and this may be a compensatory mechanism to eliminate oxidative stress, suggesting that oxidative mechanisms may play a role in the etiopathogenesis of cataract. Ucakhan [34] and his group also found SOD activity was increased in the lens capsule of patients with cataract, which may support our findings.

Previous study by Sawada et al. supported our findings, they found SOD activity was significantly increase in advanced cataract lenses that of normal human lenses [35], while present study demonstrated SOD high expressions of in senile non-diabetic cataract lenses. However, it was demonstrated that SOD activity levels were significantly increased in diabetic senile cataract group in comparison with the control group [18].

In addition, higher levels of NO end products are found in cataractous lenses of diabetic patients compared to cataractous lenses of healthy individuals [18]. The present study also report high expressions of nitric oxide synthase in cataract samples as com- 
pared to non cataract samples in senile non-diabetic samples. These observations may emphasize that high expression of NOS3 and low expression of SOD2 in could lead to catractogensis.

Combination of superoxide and NO contributes to on-diabetic cataractogenesis [32] contrary to our findings that NO participates in the formation of non-diabetic cataract as well and that SOD may protect against this type of cataract. Previous studies reported that pathogenesis of diabetic cataract associated with polyol pathway (process linked to the diabetic cataractogensis in which an enzyme aldose reductase (AR), catalyzes the reduction of glucose to sorbitol [36]. Accumulation of sorbitol leads to osmotic changes resulting in hydropic lens fibers that degenerate and form sugar cataracts. However previously Kao et al. showed NO levels in the aqueous humor increased with age and traumatic events in non-diabetic patients and could be a risk factor in cataract formation [22].

The functional association of NOS3 and SOD2 enzymes, was further validated using In Silico method. The computational prediction of interaction reveals that the number of plausible site on NOS3 with SOD2 and other molecules which may lead to more insights into the underlying mechanisms of cataract disease. They also predict a mutual mechanism of action to mediate various cellular and molecular processes that lead to cataractogensis. The association of ROS and antioxidants in non-diabetics and diabetics with cataractogenesis is still debated but we may proposed that expression of NOS3 is an important factor in the development of diabetic cataracts, and SOD2 may have a role in decreasing the incidence of cataract.

Future studies should compare the levels of ROS, antioxidants and the antioxidative enzymes, in the vitreous, aqueous humor, lens, and serum of the aged non-diabetic cataract patients. It may also necessary to evaluate the effect of interaction of NOS3 and SOD2 on the clinical outcome in human cataract.

\section{Conclusion}

The high level of NOS3 and low level of SOD2 expressions in the cataract lens of non-diabetic patients may be important factors associated with the onset of cataratogensis.

\section{Foundation}

This study was funded by grants from the Higher Education Commission (HEC) research fund. Special thanks to Layton Rahmatulla Benevolent Trust, Karachi, for providing cataract lenses.

\section{Author Contributions}

Shamim Mushtaq conceived and designed the experiments; Shamim Mushtaq, Meraj Zehra, Ayesha Khan performed the experiments \& analyzed the data; Rubina Ghani, help in collection of samples, Shamim Mushtaq \& Nikhat Ahmed Siddiqui wrote the paper. 


\section{Conflicts of Interest}

The authors declare that there are no conflicts of interest.

\section{References}

[1] Foster, A. and Resnikoff, S. (2005) The Impact of Vision 2020 on Global Blindness. Eye, 19, 1133-1135. http://dx.doi.org/10.1038/sj.eye.6701973

[2] Beatty, S., Koh, H., Phil, M., Henson, D. and Boulton, M. (2000) The Role of Oxidative Stress in the Pathogenesis of Age-Related Macular Degeneration. Survey of Ophthalmology, 3, 115-134. http://dx.doi.org/10.1016/S0039-6257(00)00140-5

[3] Mukesh, B.N., Le, A., Dimitrov, P.N., Ahmed, S., Taylor, H.R. and McCarty, C.A. (2006) Development of Cataract and Associated Risk Factors: The Visual Impairment Project. Archives of Ophthalmology, 124, 79-85. http://dx.doi.org/10.1001/archopht.124.1.79

[4] Ashok, B.T. and Ali, R. (1999) The Aging Paradox: Free Radical Theory of Aging. Experimental Gerontology, 34, 293-303. http://dx.doi.org/10.1016/S0531-5565(99)00005-4

[5] Qianqian, Y., Yong, Y., Zhaodong, C., Yonghui, T, Jun, S. and Yuzheng, H. (2015) Differential Protein Expression between Type 1 Diabetic Cataract and Age-Related Cataract Patients. Folia Biologica (Praha), 61, 74-80.

[6] Zhou, H.Y., Yan, H., Wang, L.L., Yan, W.J., Shui, Y.B. and Beebe, D.C. (2015) Quantitative Proteomics Analysis by iTRAQ in Human Nuclear Cataracts of Different Ages and Normal Lens Nuclei. Proteomics. Clinical Applications, 9, 776-786. http://dx.doi.org/10.1002/prca.201400061

[7] Harman, D. (1956) Aging: A Theory Based on Free Radical and Radiation Chemistry. The Journals of Gerontology, 11, 298-300. http://dx.doi.org/10.1093/geronj/11.3.298

[8] Chang, D., Zhang, X., Rong, S., Sha, Q., Liu, P., Han, T. and Pan, H. (2013) Serum Antioxidative Enzymes Levels and Oxidative Stress Products in Age-Related Cataract Patients. Oxidative Medicine and Cellular Longevity, 587826. http://dx.doi.org/10.1155/2013/587826

[9] Øsnes-Ringen, O., Azqueta, A.O., Moe, M.C., Zetterström, C., Røger, M., Nicolaissen, B. and Collins, A.R. (2013) DNA Damage in Lens Epithelium of Cataract Patients in Vivo and ex Vivo. Acta Ophthalmologica, 91, 652-656. http://dx.doi.org/10.1111/j.1755-3768.2012.02500.x

[10] Katta, A.V., Katkam, R.V. and Geetha, H. (2013) Lipid Peroxidation and the Total Antioxidant Status in the Pathogenesis of Age Related and Diabetic Cataracts: A Study on the Lens and Blood. Journal of Clinical and Diagnostic Research, 7, 978-981.

http://dx.doi.org/10.7860/jcdr/2013/4937.3099

[11] Kaur, J., Kukreja, S., Kaur, A., Malhotra, N. and Kaur, R. (2012) The Oxidative Stress in Cataract Patients. Journal of Clinical and Diagnostic Research, 6, 1629-1632. http://dx.doi.org/10.7860/jcdr/2012/4856.2626

[12] Sorte, K., Sune, P., Bhake, A., Shivkumar, V.B., Gangane, N. and Basak, A. (2011) Quantitative Assessment of DNA Damage Directly in Lens Epithelial Cells from Senile Cataract Patients. Molecular Vision, 17, 1-6.

[13] Beebe, D.C., Holekamp, N.M. and Shui, Y.B. (2010) Oxidative Damage and the Prevention of Age-Related Cataracts. Ophthalmic Research, 44, 155-165. http://dx.doi.org/10.1159/000316481

[14] Selin, J.Z., Lindblad, B.E., Rautiainen, S., Michaëlsson, K., Morgenstern, R., Bottai, M., Basu, S. and Wolk, A. (2014) Are Increased Levels of Systemic Oxidative Stress and Inflammation Associated with Age-Related Cataract? Antioxidants \& Redox Signaling, 21, 700 - 
704. http://dx.doi.org/10.1089/ars.2014.5853

[15] Cekić, S., Zlatanović, G., Cvetković, T. and Petrović, B. (2010) Oxidative Stress in Cataractogenesis. Bosnian Journal of Basic Medical Sciences, 10, 265-269.

[16] Nagai, N., Liu, Y., Fukuhata, T. and Ito, Y. (2006) Inhibitors of Inducible Nitric Oxide Synthase Prevent Damage to Human Lens Epithelial Cells Induced by Interferon-Gamma and Lipopolysaccharide. Biological \& Pharmaceutical Bulletin, 29, 2077-2078.

http://dx.doi.org/10.1248/bpb.29.2077

[17] Linetsky, M., Raghavan, C.T., Johar, K., Fan, X., Monnier, V.M., Vasavada, A.R. and Nagaraj, R.H. (2014) Light-Excited Kynurenines Oxidize Ascorbate and Modify Lens Proteins through the Formation of Advanced Glycation End Products: Implications for Human Lens Aging and Cataract Formation. Journal of Biological Chemistry, 289, 17111-17123. http://dx.doi.org/10.1074/jbc.M114.554410

[18] Ornek, K., Karel, F. and Buyukbingol, Z. (2003) May Nitric Oxide Molecule Have a Role in the Pathogenesis of Human Cataract? Experimental Eye Research, 76, 23-27. http://dx.doi.org/10.1016/S0014-4835(02)00268-3

[19] Kulaksizoglu, S. and Karalezli, A. (2016) Aqueous Humour and Serum Levels of Nitric Oxide, Malondialdehyde and Total Antioxidant Status in Patients with Type 2 Diabetes with Proliferative Diabetic Retinopathy and Nondiabetic Senile Cataracts. Canadian Journal of Diabetes, 40, 115-119. http://dx.doi.org/10.1016/j.jcjd.2015.07.002

[20] Li, C.Q. and Wogan, G.N. (2005) Nitric Oxide as a Modulator of Apoptosis. Cancer Letters, 226, 1-15. http://dx.doi.org/10.1016/j.canlet.2004.10.021

[21] Thiagarajan, R. and Manikandan, R. (2013) Antioxidants and Cataract. Free Radical Research, 47, 337-345. http://dx.doi.org/10.3109/10715762.2013.777155

[22] Kao, C.L., Chou, C.K., Tsai, D.C., Hsu, W.M., Liu, J.H., Wang, C.S., Lin, J.C., Wu, C.C., Peng, C.H., Chang, C.J. and Chiou, S.H. (2002) Nitric Oxide Levels in the Aqueous Humor in Cataract Patients. Journal of Cataract \& Refractive Surgery, 28, 507-512.

[23] Yousef, M.I., Awad, T.I., Elhag, F.A. and Khaled, F.A. (2007) Study of the Protective Effect of Ascorbic Acid against the Toxicity of Stannous Chloride on Oxidative Damage, Antioxidant Enzymes and Biochemical Parameters in Rabbits. Toxicology, 235, 194-202.

[24] Matsui, H., Lin, L.R., Ho, Y.S. and Reddy, V.N. (2003) The Effect of up- and down Regulation of MnSOD Enzyme on Oxidative Stress in Human Lens Epithelial Cells. Investigative Ophthalmology \& Visual Science, 44, 3467-3475. http://dx.doi.org/10.1167/iovs.02-0830

[25] Lin, D., Barnett, M., Grauer, L., Robben, J., Jewell. A., Takemoto, L. and Takemoto, D.J. (2005) Expression of Superoxide Dismutase in Whole Lens Prevents Cataract Formation. Molecular Vision, 11, 853-858.

[26] Olson, B.J. and Markwell, J. (2007) Assays for Determination of Protein Concentration. Current Protocols in Pharmacology. http://dx.doi.org/10.1002/0471141755.pha03as38

[27] Mushtaq, S., Naqvi, A.Z., Siddiqui, A.A., Carina, P., Shafqat, J. and Ahmed, N. (2007) Changes in Albumin Precursor and Hsp70 Expressions and Their Potential Role in Response to Corneal Epithelial Wound Repair. Proteomics, 7, 463-468. http://dx.doi.org/10.1002/pmic.200600446

[28] Oppermann, M., Cols, N., Nyman, T., Helin, J., Saarinen, J., Byman, I., Toran, N., Alaiya, A.A., Bergman, T., Kalkkinen, N., Gonzàlez-Duarte, R. and Jörnvall, H. (2000) Identification of Foetal Brain Proteins by Two-Dimensional Gel Electrophoresis and Mass Spectrometry Comparison of Samples from Individuals with or without Chromosome 21 Trisomy. European Journal of Biochemistry, 267, 4713-4719. http://dx.doi.org/10.1046/j.1432-1327.2000.01524.x 
[29] Kamaladevi, V., Thekkuttuparambil, L. and Ajith, A. (2016) Association of Grade of Cataract with Duration of Diabetes, Age and Gender in Patients with Type II Diabetes Mellitus. International Journal of Advances in Medicine, 3, 304-308.

[30] Sayin, N., Kara, N. and Pekel, G. (2015) Ocular Complications of Diabetes Mellitus. World Journal of Diabetes, 6, 92-108.

[31] Shrestha, R.K. (2011) Ocular Manifestations in Diabetes, a Hospital Based Prospective Study. Nepal Medical College Journal, 13, 254-256. http://dx.doi.org/10.4239/wjd.v6.i1.92

[32] Astrom, E., Marklund, S.L., Karlsson, K. and Behndig, A. (2003) Involvement of Nitric Oxide in the Formation of In Vitro Diabetic Cataract in Copper-Zinc Superoxide Dismutase Null Mice. Investigative Ophthalmology \& Visual Science, 44, 3469.

[33] Olofsson, E.M., Marklund, S.L. and Behndig, A. (2007) Glucose-Induced Cataract in CuZn-SOD Null Lenses: An Effect of Nitric Oxide? Free Radical Biology and Medicine, 42, 1098-1105. http://dx.doi.org/10.1016/j.freeradbiomed.2007.01.012

[34] Uçakhan, O.O., Karel, F., Kanpolat, A., Devrim, E. and Durak, I. (2006) Superoxide Dismutase Activity in the Lens Capsule of Patients with Pseudoexfoliation Syndrome and Cataract. Journal of Cataract \& Refractive Surgery, 32, 618-622.

http://dx.doi.org/10.1016/j.jcrs.2006.01.018

[35] Sawada, H., Fukuchi, T. and Abe, H. (2009) Oxidative Stress Markers in Aqueous Humor of Patients with Senile Cataracts. Current Eye Research, 34, 36-41. http://dx.doi.org/10.1080/02713680802500960

[36] Giacco, F. and Brownlee, M. (2010) Oxidative Stress and Diabetic Complications. Circulation Research, 107, 1058-1070. http://dx.doi.org/10.1161/CIRCRESAHA.110.223545

Submit or recommend next manuscript to SCIRP and we will provide best service for you:

Accepting pre-submission inquiries through Email, Facebook, LinkedIn, Twitter, etc.

A wide selection of journals (inclusive of 9 subjects, more than 200 journals)

Providing 24-hour high-quality service

User-friendly online submission system

Fair and swift peer-review system

Efficient typesetting and proofreading procedure

Display of the result of downloads and visits, as well as the number of cited articles

Maximum dissemination of your research work

Submit your manuscript at: http://papersubmission.scirp.org/ 